\title{
Visualization of the shielding gas flow in SLM machines by space-resolved thermal anemometry
}

\author{
Maximilian Schniedenharn \\ Fraunhofer Institute for Laser Technology, Aachen, Germany \\ Frederik Wiedemann \\ Chair for Laser Technology, Rheinisch Westfalische Technische Hochschule Aachen, Aachen, Germany, and \\ Fohannes Henrich Schleifenbaum \\ Chair for Digital Additive Production, Rheinisch Westfalische Technische Hochschule Aachen, Aachen, Germany
}

\begin{abstract}
Purpose - The purpose of this paper is to introduce an approach in measuring the shielding gas flow within laser powder bed fusion (L-PBF) machines under near-process conditions (regarding oxygen content and shielding gas flow).

Design/methodology/approach - The measurements are made sequentially using a hot-wire anemometer. After a short introduction into the measurement technique, the system which places the measurement probe within the machine is described. Finally, the measured shielding gas flow of a commercial L-PBF machine is presented.

Findings - An approach to measure the shielding gas flow within SLM machines has been developed and successfully tested. The use of a thermal anemometer along with an automated probe-placement system enables the space-resolved measurement of the flow speed and its turbulence.

Research limitations/implications - The used single-normal (SN) hot-wire anemometer does not provide the flow vectors' orientation. Using a probe with two or three hot-films and an improved placement system will provide more information about the flow and less disturbance to it.

Originality/value - A measurement system which allows the measurement of the shielding gas flow within commercial L-PBF machines is presented. This enables the correlation of the shielding gas flow with the resulting parts' quality.
\end{abstract}

Keywords Additive manufacturing, Selective laser melting, Laser powder bed fusion, Shielding gas flow

Paper type Research paper

\section{Introduction}

The additive manufacturing process laser powder bed fusion (L$\mathrm{PBF}$ ) is a powder bed-based technology which allows users to produce near-net-shape parts without the need for part-specific tools. This technology enables freedom of design which makes it attractive, e.g. for using high-performance technologies as in turbines or aircraft. In contrast to conventional technologies like milling or turning, the mechanical properties are to a great extent defined during the process. Although the resulting mechanical properties are usually similar to those of cast or wrought materials, defects (mainly pores or lack-of-fusion [LOF]), which are apparently generated randomly during the process, can weaken the part's mechanical properties.

To prevent the parts from oxidizing, the L-PBF process operates under an inert argon or nitrogen gas atmosphere. Furthermore, a directed shielding gas flow over the building

The current issue and full text archive of this journal is available on Emerald Insight at: www.emeraldinsight.com/1355-2546.htm

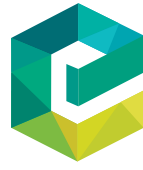

Rapid Prototyping Journal

24/8 (2018) 1296-1304

Emerald Publishing Limited [ISSN 1355-2546]

[DOI 10.1108/RPJ-07-2017-0149] platform removes process by-products (metal condensate and spatter) from the laser-powder interaction zone. While the metal condensate is sucked out of the chamber and removed from the process by filters, spatter are most likely to remain in a downstream direction on the powder bed. Insufficient shielding gas flow is considered to be one of the reasons for such defects in an otherwise stable L-PBF process (Anwar and Pham, 2016; Ferrar et al., 2012; Ladewig et al., 2016; Kong et al., 2011).

The scope of this work is to develop and test a system that enables a space-resolved measurement of the shielding gas flow speed within the chamber of an L-PBF machine under processing conditions (equal volume flow, oxygen content and temperature). If the flow distribution is known, the correlation

(C) Maximilian Schniedenharn, Frederik Wiedemann and Johannes Henrich Schleifenbaum. Published by Emerald Publishing Limited. This article is published under the Creative Commons Attribution (CC BY 4.0) licence. Anyone may reproduce, distribute, translate and create derivative works of this article (for both commercial and non-commercial purposes), subject to full attribution to the original publication and authors. The full terms of this licence may be seen at http://creativecommons.org/licences/ by/4.0/legalcode

Received 20 July 2017

Revised 20 November 2017

Accepted 9 January 2018 
between the flow distribution and the corresponding local part quality (defects affecting density, mechanical properties, [...]) can be examined, which will help to improve the next generation of L-PBF machines.

\section{Influence and measurement techniques of the shielding gas flow in laser powder bed fusion}

The defect-inducing mechanism can be roughly characterized by the place of its occurrence:

\subsection{Interaction of the process by-products with the laser beam during flight}

Metal condensate and spatter are mainly expelled from the melt pool toward the scanning direction (Matthews et al., 2016). Dependent on the scanning vectors' orientation relative to the gas flow, there is a chance of interaction of these process byproducts with the laser beam. Investigations for high-power laser beam welding (Ščeglov, 2012) have shown that the condensed metal vapor particles can cause attenuation of the laser beam of up to 10 per cent. That spatter interact with the laser beam has been shown by Anwar and Pham's study (2016) and in internal research (both using lateral high-speed imaging of the L-PBF process). When the process by-products interact with the laser beam, intensity of the laser radiation decreases at the powder bed, which thus could be a possible cause for defects.

\subsection{Influence of spatter after being redeposited}

The mechanism by which spatter can induce defects depends on the state of the spatter (molten, solidified) when impinging and the surface condition (covered with powder/already exposed). If spatter fall onto the powder bed (whether molten or solidified), they locally increase the layer thickness. In Figure 1, (left) 3D images of powder bed surfaces and the process layout (right, the numbers denote to the scanning order) are shown. The images were taken using a laser in-line profilometer which was mounted to the powder delivery axis. Both images show the same not-exposed Specimen 32. Subpart (a) was taken directly after deposition of a new powder layer, and subpart (b) was taken after exposure of Specimens 1-30. The experiment was carried out on a laboratory machine (material $=$ Ti6Al4V, laser power $=200 \mathrm{~W}$, scan speed $=1,200$ $\mathrm{mm} / \mathrm{s}$, scan line spacing $=80 \mu \mathrm{m}$, layer thickness $=30 \mu \mathrm{m}$, laser beam diameter $=80 \mu \mathrm{m})$. After exposure of 30 specimens, the surface in Figure 1 (left [b]) shows deposits (some of them are highlighted within the black circles) which consist of entrained powder or spatter resulting from exposure of Specimens 1-30. This leads to a local increase in powder layer thickness and can thus be a possible cause for LOF defects.

When molten spatter fall onto a consolidated surface, they most likely fuse with it and can therefore not be removed by the coating mechanism. Haeckel (2017) shows the formation of pores because of large spatter which adhere to the specimen's surface (maximum diameter $=200-500 \mu \mathrm{m}$ ) by the use of a laser in-line profilometer during the process. If solidified spatter fall onto a consolidated surface, it is likely that they are removed from the parts surface by the coating mechanism.

Ladewig et al. (2016) investigate the influence of the shielding gas flow on part quality. They propose that the flow above the powder bed is homogenous, and its speed is as fast as possible to prevent the by-products from interacting with the laser beam and redepositing these onto the powder bed. Anwar and Pham (2016) investigate the influence of the shielding gas flow speed (as a function of the machines gas pump setting) on the ultimate tensile strength (UTS) of AlSi10Mg specimen using a unidirectional scanning strategy. They find that an increase of the flow speed from 1.43 to $2.87 \mathrm{~m} / \mathrm{s}$ leads to a significant increase of the UTS. Furthermore, Ferrar et al. (2012) showed that a more homogeneous flow speed (investigated by simulations) distribution over the platform leads to a more homogeneous density distribution in lattice components.

To understand the influence of the shielding gas flow on the part quality, we need to examine the correlation between the process at the laser-powder interaction zone, the process byproducts and the local flow profile. The shielding gas flow within L-PBF machines can be visualized either by simulation or measurements. While the quality of the simulations strongly depends on the exact knowledge of all boundary conditions of the gas flow (geometry, volume flow, etc.), the accuracy of measurements only depends on the measurement system itself. Several technologies are capable of measuring the flow within the building chamber, which can be roughly categorized by whether the measurement device itself is invaded into the flow or not.

Common methods for noninvasive technologies are particle image velocimetry (PIV) or laser doppler anemometry. These methods track fine particles (seeds), which usually have to be

\section{Figure 1}
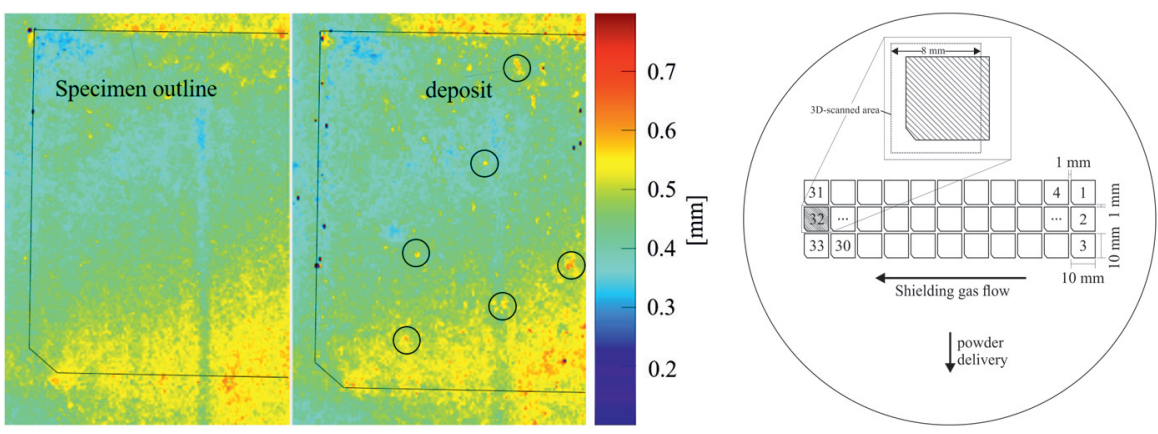
added to the flow. Flow speed and direction can be calculated from the observed movement of these particles. Previous work of the authors has shown that PIV measurements can visualize the gas flow within the test rig of a laboratory machine. But as the accessibility of commercial machines is limited and the seeder contaminates the building chamber and the filter system, noninvasive techniques are only currently used in laboratory systems.

Suitable methods for invasive measurements are hot-wire anemometry (HWA) or methods based on the measurement of differential pressure. Thermal anemometry systems have a high (up to $100 \mathrm{kHz}$ ) temporal resolution but are highly sensitive because of their thin hot wire. In Philo et al.'s study (2015), a thermal anemometer is used to measure the flow within a test rig of a Renishaw L-PBF machine. However, no further information on the measurement setup (e.g. anemometer model, calibration, measurement frequency and time) or a discussion of the results is presented. Differential pressure probes are far more robust but are not genuinely suited for measuring low flow velocities because of the low dynamic pressure generated.

As the modification of commercial L-PBF machines is not favored, we present here a measurement setup that can be fitted into the most commercial and laboratory L-PBF machines without structural changes. It is based on a thermal anemometer, moved through the building chamber by an automated probe-placement system. This enables sequential, space-resolved, high-frequency measurements of the flow speed.

\section{Methodology}

Calibration of the anemometer probes is carried out with a custom-built calibration unit in argon gas. The result is a fourth-order polynomial that describes the correlation between the bridge output voltage $\mathrm{U}_{\mathrm{b}}$ and the flow speed. Temperature and pressure correction are applied to compensate for the differences between calibration and measurement. Because of the high-frequency response of the hot-wire anemometer (HWA), speed and turbulence (deviation from the speed over time) can be measured.

\subsection{Thermal anemometry}

Thermal anemometry systems are based on the cooling effect of a heated thin wire or film caused by the motion of its surrounding fluid. For the following work, a single-normal (SN) anemometry system [TSI 1750A module with 1201-6 measurement probes (Figure 2)] was used. The 1750A module only provides an output voltage that is proportional to the speed of the probe's surrounding fluid. The correlation between this voltage and the actual flow speed is achieved by calibrating the probe in argon gas. The measurement probe used, 1201-6, is a straight hot-film probe that is more durable than hot-wire probes. The maximum frequency response of hot films is about $50 \mathrm{kHz}$, and the 16-bit A/D converter (National Instruments USB-6211) has a maximum sample rate of $250 \mathrm{kHz}$, with a minimum resolvable voltage of $2.69 \mathrm{mV}$ (National Instruments, 2017).

The bridge output voltage is dependent on the magnitude of the velocity vector and on its orientation relative to the hot film.

\section{Figure 2}

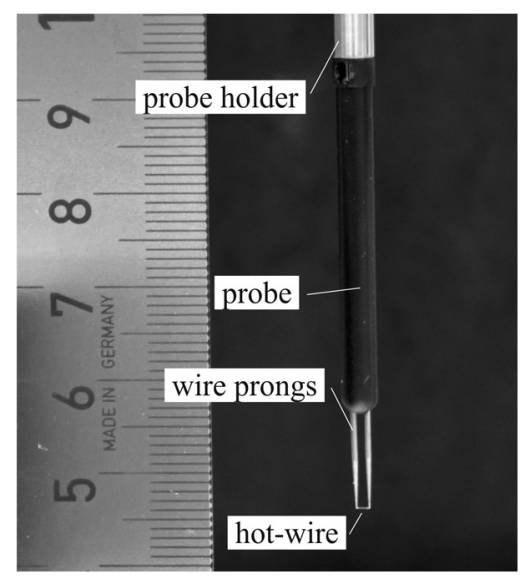

A sketch of a SN-HWA probe and its coordinate system $\left(\mathrm{x}_{\mathrm{p}}, \mathrm{y}_{\mathrm{p}}\right.$, $z_{p}$ ) used throughout this work is shown in Figure 3. Any velocity vector $\mathrm{V}$ can be split into its components normal $\left(\mathrm{V}_{\mathrm{N}}\right)$, tangential $\left(\mathrm{V}_{\mathrm{T}}\right)$ and binormal $\left(\mathrm{V}_{\mathrm{B}}\right)$ to the hot-film. The hotwires response is different for each of these three components, resulting in an effective cooling velocity $\mathrm{V}_{\text {eff }}$ which can be expressed by the Jørgensen's equation:

$$
V_{e f f}^{2}=V_{N}^{2}+k^{2} V_{T}^{2}+h^{2} V_{B}^{2}
$$

where $\mathrm{k}$ and $\mathrm{h}$ are the sensor's yaw and pitch coefficients with standard values for a plated hot wire being $\mathrm{k}=0.2$ and $\mathrm{h}=1.05$ (Bruun, 1996). Therefore, using an SN-HWA probe, it cannot be distinguished whether a change in $V_{\text {eff }}$ is caused by a change in magnitude or by a change in orientation of $\mathrm{V}$ relative to the hot film (using an HWA probe with two or three films allows for the determination of the flow's orientation but is behind the scope of this work).

To calculate the accurate flow speed from the bridge output voltage, the signal has to be conditioned according to the postprocessing chain depicted in Figure 4:

- Temperature correction: The $1750 \mathrm{~A}$ is operated with a constant overheat ratio; therefore, the bridge output voltage $U_{b}$ has to be temperature-corrected (Jørgsen, 2002) according to the difference between the flow's temperature during calibration and measurement.

Figure 3

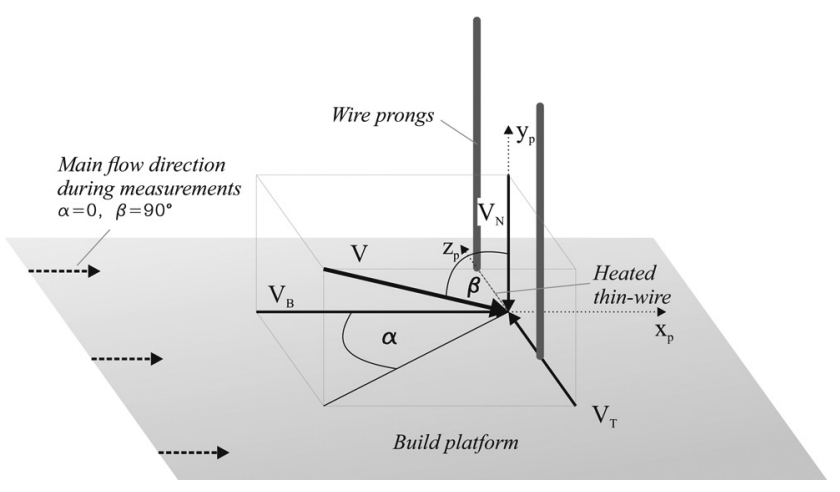


Figure 4

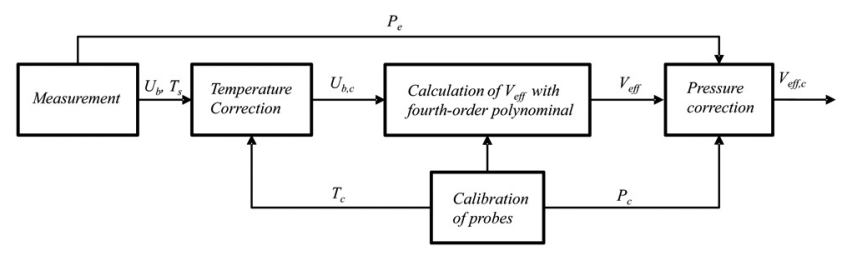

- Using the calibration curve, we calculated the effective cooling speed $V_{\text {eff. }}$.

- Finally, $V_{\text {eff }}$ is corrected according to the difference in ambient pressure between calibration and measurement, resulting in $V_{\text {eff,c }}$.

\subsection{Temperature and pressure correction}

It is assumed that the temperature change within the time of measurement can be neglected because there are no varying heat sources or sinks during measurement. The difference in temperature between calibration and measurement is corrected with a single value for the temperature during measurement according to:

$$
U_{b, c}=U_{b} \sqrt{\frac{T_{s} T_{c}}{\mathrm{~T}_{s} T_{e}}}
$$

$U_{b}[\mathrm{~V}]=$ bridge output voltage;

$U_{b, c}[\mathrm{~V}]=$ temperature corrected bridge output voltage;

$T_{s}[\mathrm{~K}]=$ film temperature;

$T_{c}[\mathrm{~K}]=$ fluid temperature during calibration; and

$T_{e}[\mathrm{~K}]=$ fluid temperature during measurement.

The pressure is corrected by the following equation:

$$
V_{e f f, c}=\frac{P_{c}}{P_{e}} V_{e f f}
$$

$$
\begin{aligned}
V_{e f f, c}[\mathrm{~m} / \mathrm{s}] & =\text { pressure-corrected effective cooling speed; } \\
V_{\text {eff }}[\mathrm{m} / \mathrm{s}] & =\text { effective cooling speed; } \\
P_{c}[\mathrm{~Pa}] & =\text { atmospheric pressure during calibration; and } \\
P_{e}[\mathrm{~Pa}] & =\text { atmospheric pressure during measurement. }
\end{aligned}
$$

Temperature and pressure correction are applied, while postprocessing each recorded sample of $U_{b}$.

\subsection{Calibration of probes}

Each probe has to be individually calibrated. This was carried out by placing the probe in a flow with known speed and measuring the bridge output voltage $\left(\mathrm{U}_{\mathrm{b}}\right)$ along with the surrounding pressure and the temperature of the flow. To calibrate the probes for argon gas, a custom-built calibration unit was used (Figure 5). As the surrounding of the units' exit is empty (except the anemometer probe) and stagnant, the flow at the nozzles exit can be described as a free jet. Within the potential core of a free jet, the flow velocity is equal to the flow velocity at the nozzle exit (Tennekes and Lumley, 1999). The unit is made of a nozzle with no constant section to prevent flow profile relaxation (Todde et al., 2009) and to ensure a top-hatlike flow profile at its exit. A pipe ensures a preferably laminar flow into the nozzle.
Figure 5

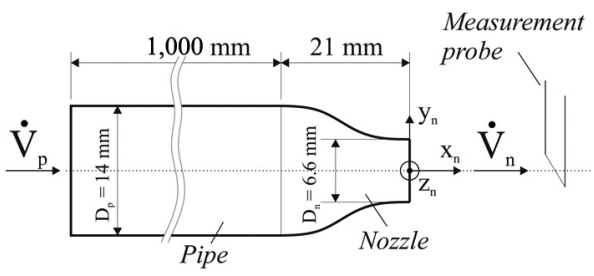

The nozzles exit diameter $D_{\mathrm{n}}$ is fixed at $6.6 \mathrm{~mm}$, the inner pipe diameter $D_{\mathrm{p}}$ is set to $14 \mathrm{~mm}$. Taking into account the Renyolds number for the transition from laminar to turbulent flow regime $\operatorname{Re}_{n \text {, max }} \sim 2,300$, we calculate the mean exit speed at the nozzle $\bar{V}_{n, \max }$ as (with the dynamic viscosity of $\operatorname{argon}$ for $p=1$ bar, $t=298.15 \mathrm{~K}, v=13.99 \mu \mathrm{m}^{2} / \mathrm{s}$ [Lemmon et al., 1997]):

$$
\bar{V}_{n, \max }=\frac{R e_{n, \max } * \nu}{D_{n}}=\frac{2300 * 13.99 \mu \frac{\mathrm{m}^{2}}{\mathrm{~s}}}{0.0066 \mathrm{~m}}=4.88 \frac{\mathrm{m}}{\mathrm{s}}
$$

To ensure a laminar flow into the nozzle, the pipe length $l_{\mathrm{p}}$ is calculated according to Durst et al. (2005):

$$
\begin{gathered}
l_{p}=D_{p} *\left((0.619)^{1.6}+\left(0.0567 * R e_{p}\right)^{1.6}\right)^{\frac{1}{1.6}} \\
\bar{V}_{p}=\frac{\dot{V}_{p}}{A_{p}}=\frac{A_{n} * \bar{V}_{n, \max }}{A_{p}}=\frac{0.0033^{2} \mathrm{~m}^{2} * \pi * 4.88 \frac{\mathrm{m}}{\mathrm{s}}}{0.007^{2} \mathrm{~m}^{2} * \pi}=1.08 \frac{\mathrm{m}}{\mathrm{s}}
\end{gathered}
$$

where $R e_{\mathrm{p}}$ is the Reynolds number of the pipe flow and $D_{\mathrm{p}}$ the pipe diameter. $R e_{\mathrm{p}}$ is derived from the conservation of mass (and considering the flow to be incompressible, as Mach number $<0.3$ ) requiring the volume flow through the nozzle $\dot{V}_{n}$ to be equal the volume flow through the pipe $\dot{V}_{p}$. From equation (4), we can calculate the mean flow speed within the pipe $\bar{v}_{p}$ where $A_{\mathrm{p}}$ and $A_{\mathrm{n}}$ are the cross-section areas of the pipe and the nozzle, respectively. Thereby, $R e_{\mathrm{p}}$ yields:

$$
\operatorname{Re}_{p}=\frac{D_{p} * \bar{V}_{p}}{\nu}=\frac{0.014 m * 1.08 \frac{\mathrm{m}}{\mathrm{s}}}{13.99 \mu \frac{\mathrm{m}^{2}}{\mathrm{~s}}}=1080.77
$$

Using equation (5), $l_{\mathrm{p}}=0.86 \mathrm{~m}$, the final pipe length is set to 1 $\mathrm{m}$ to gain more reliability. For all calibrations the probe is placed along the jets centerline at $\mathrm{X}=1$, the positioning of the probe along the centerline $\left(y_{\mathrm{n}}=z_{\mathrm{n}}=0\right)$ is carried out visually using manually adjustable stages.

The volume flow $\dot{V}_{p}$ through the pipe is measured using a Vögtlin Red-y Compact GCR-A (Vögtlin) volume flow meter with a total accuracy of \pm 2 per cent of its terminal flow rate (20 l/min) (Vögtlin Instruments $\mathrm{GmbH}$ ).

For calibration, the probes are placed within the flow in the same direction as during measurements (relative to the main flow direction: $\alpha=0^{\circ}$ (yaw), $\beta=90^{\circ}$ (pitch); Figure 5. So that the speed from the temperature-corrected bride output Voltage $U_{\mathrm{b}, \mathrm{c}}$ can be calculated, the calibration curves are fitted with a fourth-order polynomial: 


$$
V_{e f f}=A U_{b, c}^{4}+B U_{b, c}^{3}+C U_{b, c}^{2}+D U_{b, c}+E
$$

Figure 6 shows the measurement points (circles) and the fourthorder calibration curve (continuous line) for the probe used throughout this work. Used gas was argon, ambient pressure and gas temperature were recorded during measurement for future correction (Figure 4).

\subsection{Inherent turbulence of the measurement}

With the Reynolds decomposition, a turbulent flow speed $V$ can be split into a mean flow speed $\bar{V}$ and its root mean square (RMS) $V^{\prime}$ [equation (9)]. To emphasize the significance of the RMS as a measurement of the flow's turbulence, we will refer to the RMS as turbulence component throughout this work:

$$
V=\bar{V}+V^{\prime}
$$

with

$$
\begin{gathered}
\bar{V}=\frac{1}{n} \sum_{i=1}^{n} V_{i} \\
V^{\prime}=\sqrt{\frac{1}{n} \sum_{i=1}^{n}\left(V_{i} \bar{V}\right)^{2}}
\end{gathered}
$$

The turbulence intensity $T_{\mathrm{u}}$ describes the turbulent component relative to the mean flow speed:

$$
T_{u}=\frac{V^{\prime}}{\bar{V}}
$$

$V[\mathrm{~m} / \mathrm{s}]=$ flow speed;

$\bar{V}[\mathrm{~m} / \mathrm{s}]=$ mean flow speed;

$V^{\prime}[\mathrm{m} / \mathrm{s}]=$ turbulent component of the flow;

$T_{u}[-]=$ turbulence intensity; and

$n[-]=$ number of sample points.

\section{Figure 6}

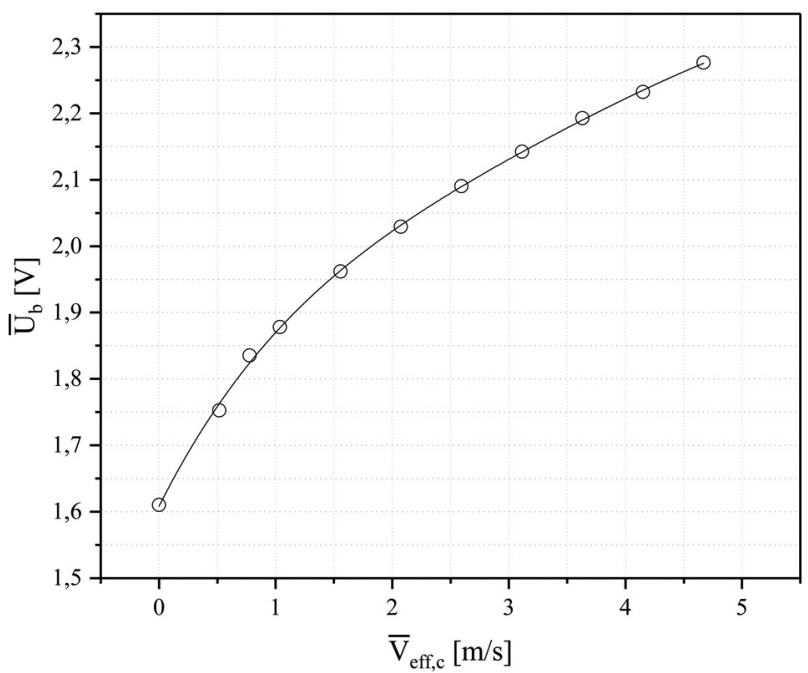

Turbulent component and turbulence intensity during calibration of the probe used are shown in Figure 7. It can be seen that the turbulent component increases with higher flow speed. For a flow speed of $4.81 \mathrm{~m} / \mathrm{s}$, the Reynolds number yields 2,269 with $T_{\mathrm{u}}=0.71$ per cent (Figure 7 ). This agrees with Todde et al.'s study (2009) which measure $T_{\mathrm{u}}<2$ per cent at $X \leq 1$ for $\operatorname{Re}<6,750$ within a free jet using a thermal anemometer (made in-house, wire length $=1.25 \mathrm{~mm}$ placement within the flow is $\alpha=0^{\circ}, \beta=90^{\circ}$ ) placed at the centerline of a free jet. It is behind the scope of this work to distinguish whether the turbulent component emerges from the influence of the wire prongs because of $\beta=90^{\circ}$ (Adrian et al., 1984) or from the flow itself.

Regarding the calibration the following conclusions can be drawn:

- Meeting the condition that the Reynolds number at the nozzle exit is $<2,300$, the maximum speed of calibration unit is $4.88 \mathrm{~m} / \mathrm{s}$ which is within the expected range of flow speeds within L-PBF machines.

- The inherent $T_{\mathrm{u}}$ of the calibration is $<2$ per cent.

As it cannot be distinguished whether this is a result of the flow itself or a result of the placement of the probe itself within the flow, values below $T_{\mathrm{u}}=2$ per cent within the later measurement will be excluded from interpretation.

\subsection{Measurement frequency and time}

As the HWA only measures the effective cooling speed at a single point, multiple measurements at different locations have to be made sequentially to visualize the gas flow within the building chamber. The final result is, therefore, not a snapshot of the gas flow distribution at a certain point in time but composed from separate measurements over the total measurement period [usually several hours (Table I)]. As no effects which can alter the volumetric flow through the shielding gas system (e.g. filter clogging by metal condensate) occur during measurement, it is expected that a sequential measurement of the flow provides reliable results. However, fluctuations of the flow speed can occur on a much shorter time scale. Thus, the measurement period for each individual point needs to be longer than the longest period of these fluctuations within the measurement domain. Figure 8

\section{Figure 7}

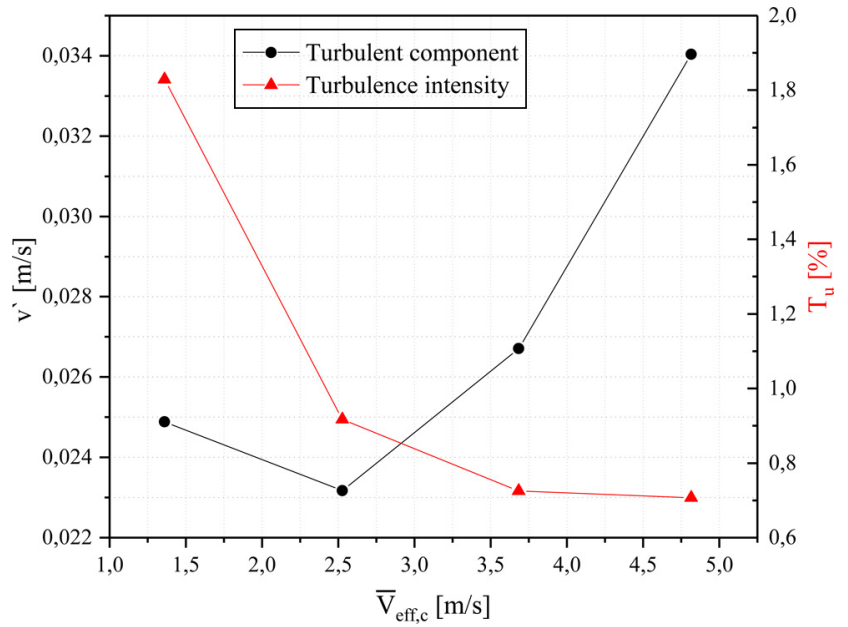


Table I Measurement conditions

\begin{tabular}{lll}
\hline Name & Unit & Value \\
\hline $\boldsymbol{\Delta} \boldsymbol{x}$ & {$[\mathrm{mm}]$} & 8.88 \\
No. of steps in $\boldsymbol{x}$ & {$[-]$} & 18 \\
$\Delta \boldsymbol{y}$ & {$[\mathrm{mm}]$} & 8.88 \\
No. of steps in $\boldsymbol{y}$ & {$[-]$} & 23 \\
$\boldsymbol{\Delta} \boldsymbol{N o}$ & {$[\mathrm{mm}]$} & 3.78 \\
No. of steps in $\boldsymbol{z}$ & {$[-]$} & 18 \\
Samples/point & {$[-]$} & 1,000 \\
Measurement frequency & {$[\mathrm{Hz}]$} & 1,000 \\
Type of HWA probe & {$[-]$} & Straight hot-film \\
Total measurement time & {$[\mathrm{h}]$} & approximately 10 \\
\hline
\end{tabular}

\section{Figure 8}

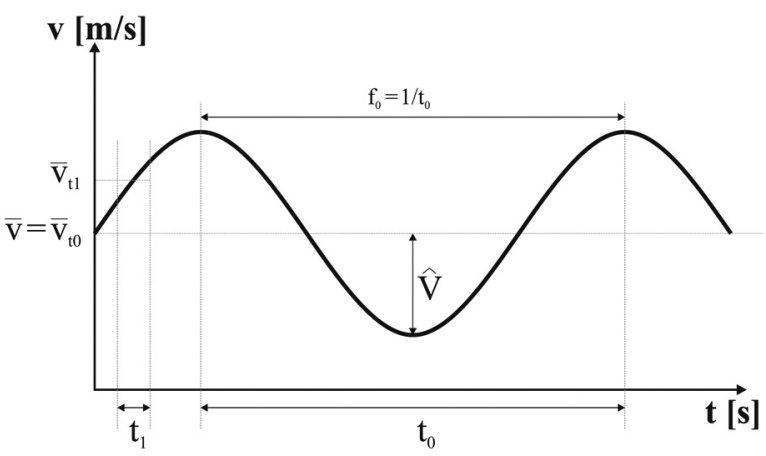

shows a sine wave as an example of a flow with variable speed over time with a mean speed of $\bar{V}$, an amplitude of $\hat{V}$ and a frequency of $f_{0}$. If the measurement time is $t_{1}$, only a fraction of the sine wave is captured, and thus the mean value $\bar{V}_{t 1}$ differs from measurements made at time intervals longer than $1 / f_{0}$. Figure 9 shows the time and frequency domain of the anemometer's bridge output (measurement $=50 \mathrm{kHz}, t=5 \mathrm{~s}$ ) at a single point in the measurement domain. It can be seen that there are no significant frequencies present, which indicates a noisy signal. The time of measurement only has, therefore, a minor impact on the resulting

\section{Figure 9}
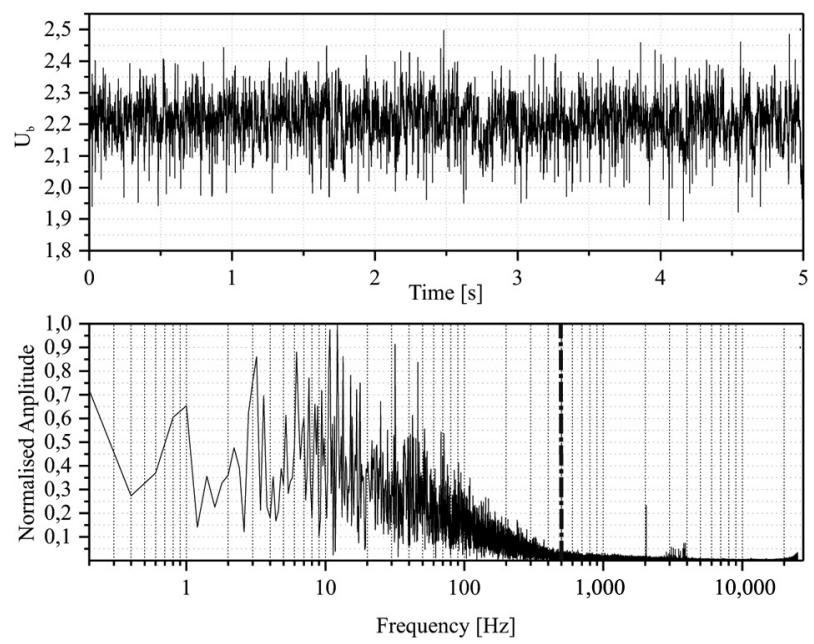

output. Furthermore, above approximately $500 \mathrm{~Hz}$ [dot and dashed line, frequency representation (Figure 9)], there are no significant components in the signal.

For all experiments presented in this work, at each measurement point, 1,000 samples were recorded at a frequency of $1 \mathrm{kHz}$. Those settings do not allow for investigation of long-term $(f<0.5 \mathrm{~Hz})$ or short-term $(f>500$ $\mathrm{Hz}$ ) fluctuations. However, the results presented aim at the depiction of the flow distribution within a plane or along a single axis. Because of the number of measurement points [total number of 7,452, (Table I)] fluctuations at a single point are therefore of minor impact on the desired representation of the flow. All depictions of the flow speed are based on the mean value of the pressure-corrected effective flow speed $\bar{v}_{\text {eff,c }}$.

\subsection{Probe-placement system}

To make the HWA measurements at predefined points within the building chamber, an automated probe-placement system has been designed. A schematic drawing is shown in Figure 10. It is based on a cartesian coordinate system with three axes for traversing the measurement probe in the $x, y$ and $z$ directions. Its design allows it to be mounted to the building chamber's ceiling, so that the influence of the system on the shielding gas flow is kept at a minimum level. The four $(2 \times x, 1 \times y, 1 \times z)$ stepper motors are operated using an Arduino-Mega 2560 microcontroller board, and the visualization is carried out using paraview (Hansen, 2005).

\subsection{Measurement setup}

The experiments were carried out in the building chamber of a commercial L-PBF machine under processing conditions (equal oxygen content and shielding gas flow). All powder was removed from the chamber prior to the measurements to avoid damaging the HWA because of its contact with powder particles.

In Table I, measurement conditions used are shown. Although no user input was required during the measurements, a tradeoff between measurement accuracy (here: resolution of the measurement domain in time and space) and the total measurement time had to be found. Previous experiments using the presented setup have shown that, considering the same increment in length, the flow speed changes more rapidly along

Figure 10

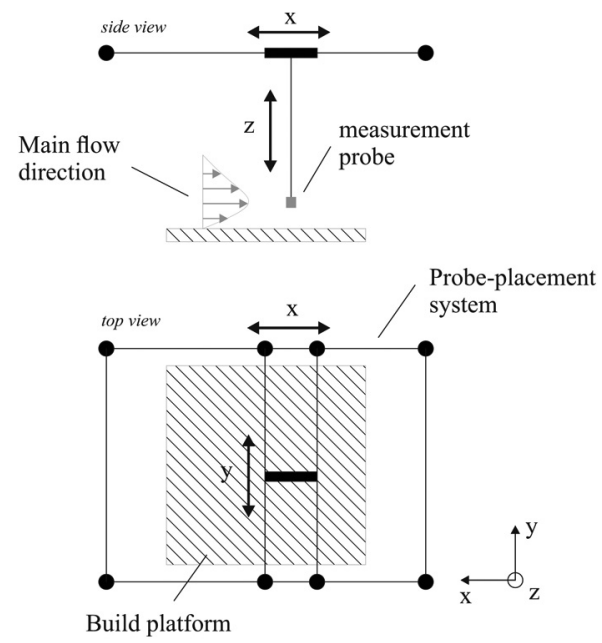


the $z$-axis than along the $x$ - and $y$-axes. To resolve those different flow speed variations, we therefore choose different domains resolutions $(\Delta x / \Delta y / \Delta z)$ along $x / y$ (coarser) and $z$ (finer). The measurement conditions used are shown in Table I, and odd numbers for the increments in $x, y$ and $z$ are a result of the transmission ratio from the stepper motors' increments to the corresponding linear movement.

\section{Results}

\subsection{Flow visualization}

Figure 11 depicts the mean flow in six planes parallel to the building platform ( $z$-distance to powder bed 5-30 mm). For all figures, the flow is directed from top (inlet) to bottom (suction). The range of the flow speed is roughly between 1 to $4 \mathrm{~m} / \mathrm{s}$. An inhomogeneity along the $x$-axis can be seen within the first three depicted planes, with a higher flow speed on the left side. With increasing distance from the building platform, the flow speed distribution along the $x$-axis becomes more homogeneous.

The turbulent component and the turbulence intensity are depicted in Figures 12 and 13, respectively. The turbulent component increases with flow speed, showing an inhomogeneous distribution over each plane. In Figure 14, the turbulent component is depicted over the mean flow speed for every measurement point. The red line shows the same relationship for the calibration of the probe. It can be clearly seen that the turbulent component during the measurement is significantly higher than during calibration which is therefore an inherent feature of the flow. If the turbulent component is divided by the specific mean flow speed (resulting in the turbulence intensity), the distribution over the planes becomes

\section{Figure 11}

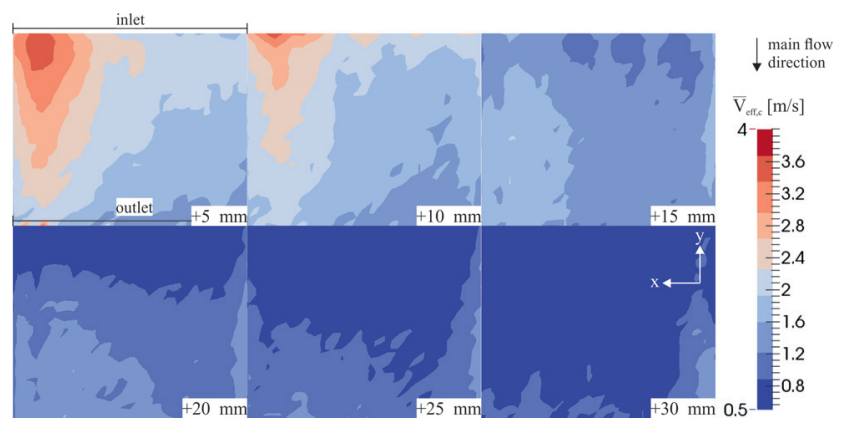

\section{Figure 12}

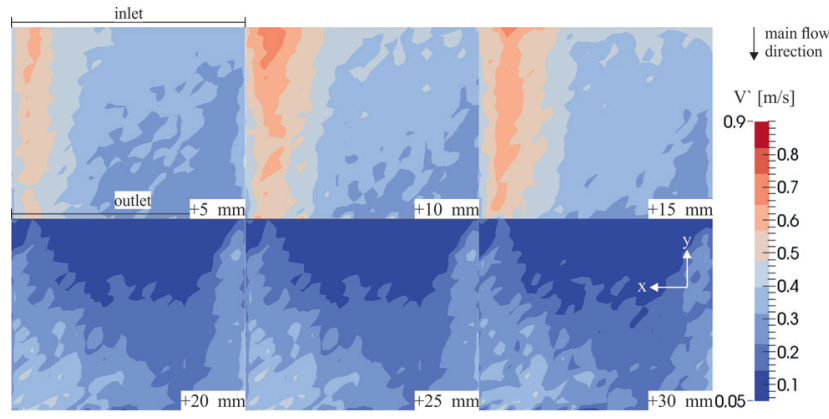

\section{Figure 13}

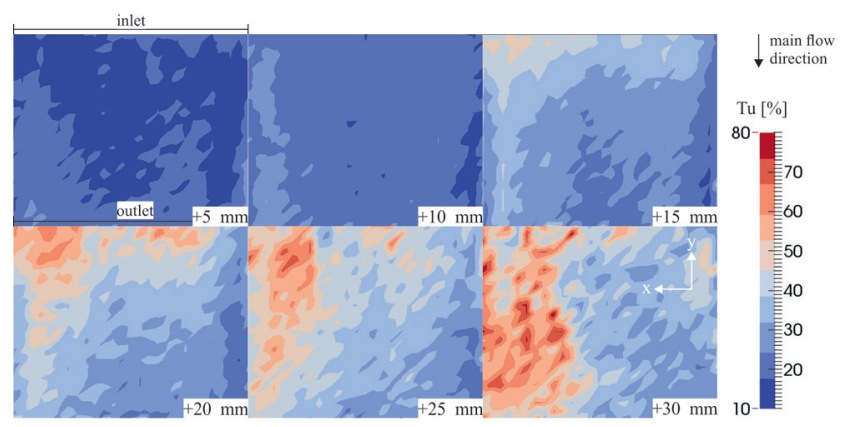

\section{Figure 14}

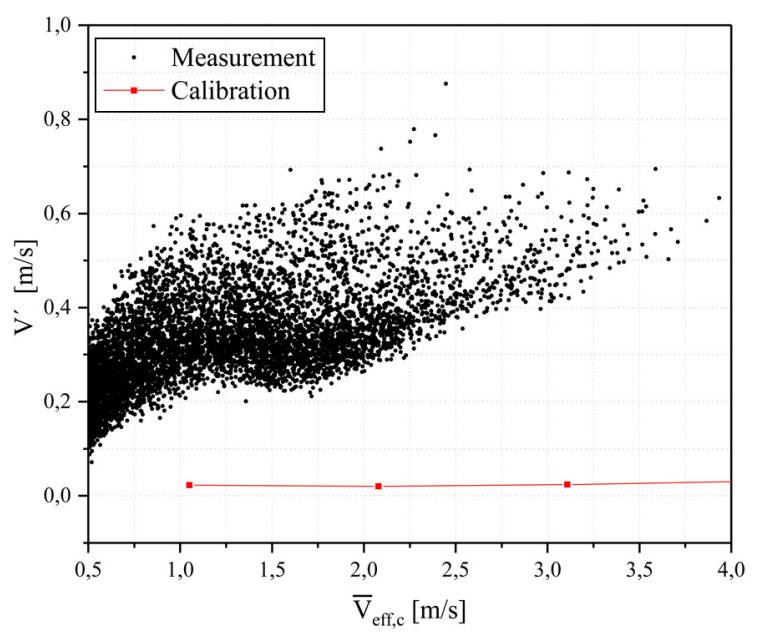

homogeneous. This can be explained by the increase in the turbulent component as the flow speed increases.

Figure 15 depicts the volume flow $\dot{V}_{x y}$ above the platform. It describes the volume which passes through a plane defined by:

\section{Figure 15}

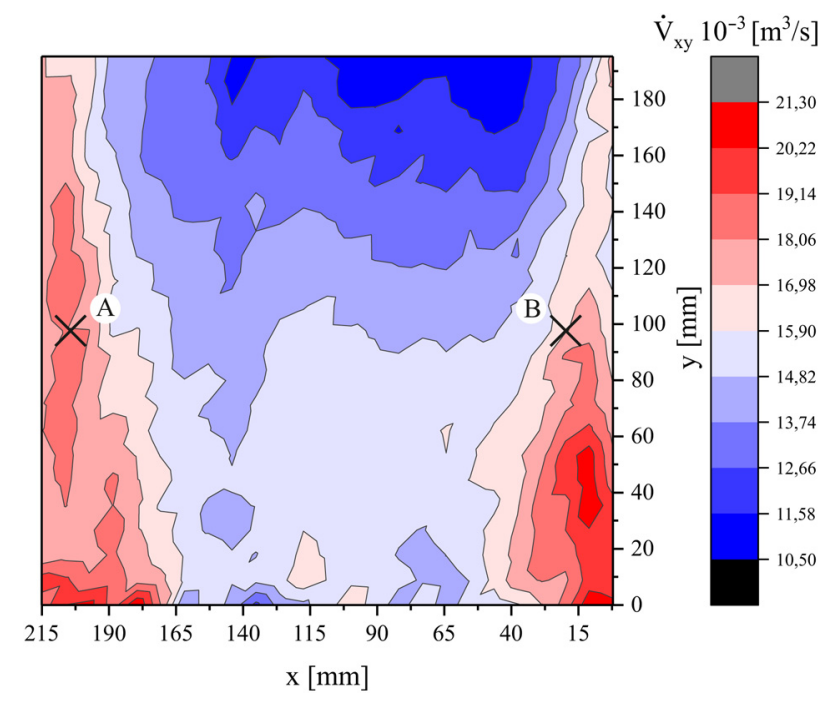




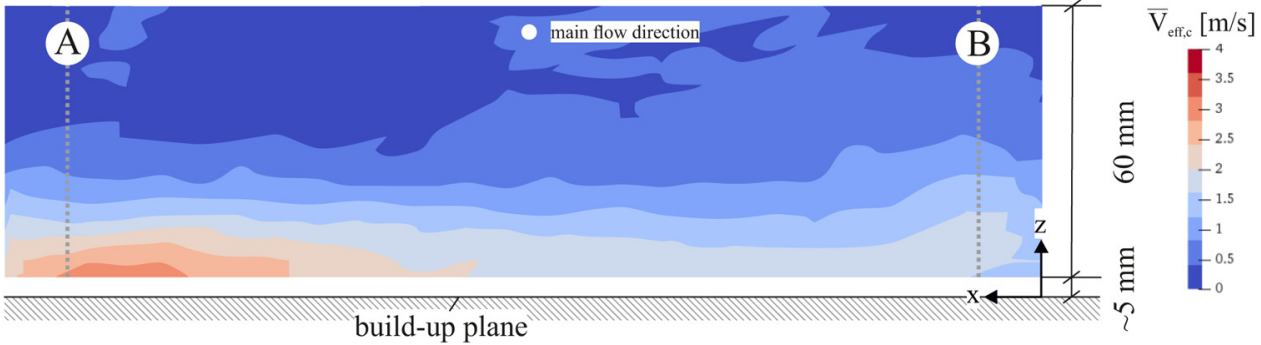

$$
\dot{V}_{x y}=\sum_{i=1}^{i=n} \Delta x * \Delta z * \bar{V}_{e f f, c}
$$

$\dot{V}_{\mathrm{xy}}\left[\mathrm{m}^{3} / \mathrm{s}\right]=$ volume flow at location $x y$; and

$n=$ number of domain points along $z$-direction

$\dot{V}_{x y}$ thereby sums up all measurement points along the $z$-direction at a location defined by $x y$ and allows one to interpret the whole flow field parallel to the building plane at once. Clearly, the volume flow distribution along the $x$-axis is not as inhomogeneous as it initially seems from Figure 11. On the left and right sides, two jets with an increased volume flow are present, resulting in a mirrored distribution of the volume flow along $x_{\max } / 2$. Furthermore, the volume flow increases almost linearly along its path because the volume through the suction is filtered from dust and particles and fed into the chamber through the nozzle and an additional bypass. This requires the volume flow through the suction to be bigger or equal to the volume flow through the nozzle.

Figure 16 shows the flow speed distribution along a single $x z$-plane (perpendicular to the main flow direction) for the middle of the measurement domain $\left(y_{\max } / 2\right)$. In addition, two flow profiles, " $\mathrm{A}$ " and " $\mathrm{B}$," are depicted in Figure 17 (locations shown as marked in Figure 15 and dashed gray lines in Figure 16). Profile "A" shows a maximum flow speed of $2.92 \mathrm{~m} / \mathrm{s}$ (however, as the flow profile shows no global maximum, the actual maximum flow speed might be higher toward $z<5 \mathrm{~mm}$ ) with $\dot{V}_{x y, A}=10.96 \times 10^{-3} \mathrm{~m}^{3} / \mathrm{s}$, Profile "B" has a maximum flow speed of $1.81 \mathrm{~m} / \mathrm{s}$ (global

\section{Figure 17}

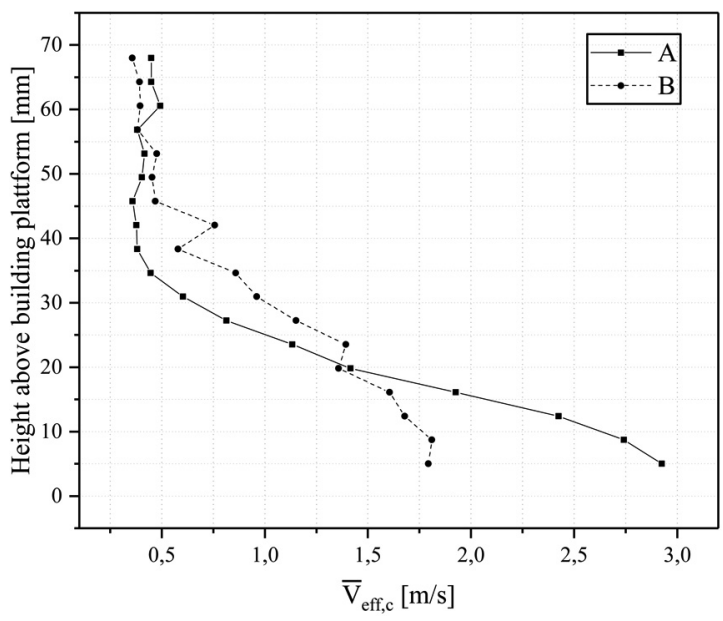

maximum is reached at $z=8.7 \mathrm{~mm}$ ) with $\dot{V}_{x y, B}=10.19 \times$ $10^{-3} \mathrm{~m}^{3} / \mathrm{s}$. Note that the difference between $\dot{V}_{x y, A}$ and $\dot{V}_{x y, B}$ is small in comparison to the range of the volume flow in the $x y$-plane (ten aussian-shaped distribution with its 50 per cent percentile $\dot{V}_{x y, 50 \text { percent }}=8.91 \times 10^{-3} \mathrm{~m}^{3} / \mathrm{s}$, ranging from $\dot{V}_{x y, 10 \text { percent }}=7.28 \times 10^{-3} \mathrm{~m}^{3} / \mathrm{s}$ to $\dot{V}_{x y, 0 \text { percent }}=10.70 \times 10^{-3}$ $\mathrm{m}^{3} / \mathrm{s}$. The comparison of the flow Profiles " $\mathrm{A}$ " and " $\mathrm{B}$ " demonstrate that different flow profiles with variable and/or equal properties are present within the flow.

\section{Conclusion and outlook}

A system which allows for space-resolved measurement of the shielding gas flow speed within the chamber of an L-PBF machine under processing conditions has been presented and successfully tested. This was attained by coupling an automated probe-placement system with a SN-thermal hotfilm anemometer. The hot-film probe used was calibrated to argon gas using a self-developed calibration unit.

The main focus of future work will be the comparison of the gas flow in different L-PBF machines with the corresponding process stability and part quality. Moreover, using a multidimensional anemometer will give more insight in the flow field. This will help us better understand the L-PBF process and lead to the next generation of shielding gas flow systems in L-PBF machines.

\section{References}

Adrian, R.J., Johnson, R.E., Jones, B.G., Merati, P. and Tung, A.T.-C. (1984), "Aerodynamic disturbances of hot-wire probes and directional sensitivity", Fournal of Physics E: Scientific Instruments, Vol. 17 No. 1, pp. 62-71.

Anwar, A.B. and Pham, Q.-C. (2016), "Selective laser melting of AlSi10Mg: effects of scan direction, part placement and inert gas flow velocity on tensile strength", fournal of Materials Processing Technology, Vol. 240, pp. 388-396.

Bruun, H.H. (1996), Hot-Wire Anemometry: Principles and Signal Analysis, Oxford science publications, reprint, Clarendon Press, Oxford.

Durst, F., Ray, S., Ünsal, B. and Bayoumi, O.A. (2005), "The development lengths of laminar pipe and channel flows", fournal of Fluids Engineering, Vol. 127 No. 6, p. 1154.

Ferrar, B., Mullen, L., Jones, E., Stamp, R. and Sutcliffe, C.J. (2012), "Gas flow effects on selective laser melting (SLM) manufacturing performance", fournal of Materials Processing Technology, Vol. 212 No. 2, pp. 355-364. 
Haeckel, F. (2017), “Technologische herausforderungen für die automobile serienfertigung im laserstrahlschmelzen", in Kynast, M., Witt, G. and Eichmann, M. (Eds), Proceedings of the 14th Rapid.Tech Conference, Rapid.Tech - International Trade Show \& Conference for Additive Manufacturing, Erfurt, Germany, 20 - 22 June, Carl Hanser Verlag GmbH $\mathcal{E}$ Co. KG, München, pp. 435-446.

Hansen, C.D. (Ed.) (2005), The Visualization Handbook, Elsevier, Amsterdam.

Jørgsen, F.E. (2002), "How to measure turbulence with hotwire anemometers. -a practical guide", available at: www. dantecdynamics.com/docs/support-and-download/researchand-education/practicalguide.pdf (accessed 1 May 2017).

Kong, C.-J., Tuck, J.C., Ashcroft, I.A., Wildman, R.D. and Hauge, R. (2011), "High density Ti6Al4V via SLM processing: microstructure and mechanical properties", paper presented at Annual International Solid Freeform Fabrication (SFF) Symposium, 08-10 August, Austin, TX. (accessed 20 October 2017).

Ladewig, A., Schlick, G., Fisser, M., Schulze, V. and Glatzel, U. (2016), "Influence of the shielding gas flow on the removal of process by-products in the selective laser melting process", Additive Manufacturing, Vol. 10, pp. 1-9.

Lemmon, E.W., McLinden, M.O. and Friend, D.G. (1997), "Thermophysical properties of fluid systems", NIST Chemistry WebBook, NIST Standard Reference Database 69, National Institute of Standards and Technology, Gaithersburg, MD.

Matthews, M.J., Guss, G., Khairallah, S.A., Rubenchik, A.M., Depond, P.J. and King, W.E. (2016), "Denudation of metal powder layers in laser powder bed fusion processes", Acta Materialia, Vol. 114, pp. 33-42.

Philo, A., Lavery, N., Brown, S.G.R., Cherry, J., Sienz, J., Joannou, J. and Sutcliffe, C. (2015), "Comparison and validation of gas flow models in a powder bed selective laser melting process", in Gill, A.J. and Sevilla, R. (Eds), Proceedings of The 23rd UK Conference of the Association for Computational Mechanics in Engineering, University of Swansea, pp. 189-192.

Ščeglov, P. (2012), "Study of vapour-plasma plume during high power fiber laser beam influence on metals", Zugl.: Moskau, Univ., Diss., 2012, BAM-Dissertationsreihe, Bundesanstalt für Materialforschung und -prüfung (BAM), Berlin, Vol. 88 .

Tennekes, H. and Lumley, J.L. (1999), A First Course in Turbulence, 17. print, MIT Press, Cambridge, MA.

Todde, V., Spazzini, P.G. and Sandberg, M. (2009), "Experimental analysis of low-Reynolds number free jets", Experiments in Fluids, Vol. 47 No. 2, pp. 279-294.

\section{Further reading}

Vögtlin Instruments $\mathrm{GmbH}$ (2018), “Thermal mass flow meters red-y compact series", available at: www.voegtlin. com/data/329-2017_en_infocompact.pdf (accessed 26 October 2017).

\section{Corresponding author}

Maximilian Schniedenharn can be contacted at: maximilian.schniedenharn@ilt.fraunhofer.de 